\title{
Mating allocations in Nordic Red Dairy Cattle using genomic information
}

\author{
C. Bengtsson, ${ }^{1,2 *}$ H. Stålhammar, ${ }^{1} \oplus$ J. R. Thomasen, ${ }^{1} \oplus$ S. Eriksson, ${ }^{2} \oplus$ W. F. Fikse, ${ }^{3} \oplus$ and E. Strandberg ${ }^{2} \odot$ \\ ${ }^{1}$ VikingGenetics, VikingGenetics Sweden AB, 53294 Skara, Sweden \\ ${ }^{2}$ Department of Animal Breeding and Genetics, Swedish University of Agricultural Sciences, Box 7023, 75007 Uppsala, Sweden \\ ${ }^{3}$ Växa Sverige, Växa Sverige, Box 288, 75105 Uppsala, Sweden
}

\section{ABSTRACT}

In this study, we compared mating allocations in Nordic Red Dairy Cattle using genomic information. We used linear programming to optimize different economic scores within each herd, considering genetic level, semen cost, the economic impact of recessive genetic defects, and genetic relationships. We selected 9,841 genotyped females born in Denmark, Finland, or Sweden in 2019 for mating allocations. We used 2 different pedigree relationship coefficients, the first tracing the pedigree 3 generations back from the parents of the potential mating and the second based on all available pedigree information. We used 3 different genomic relationship coefficients, 1 SNP-by-SNP genomic relationship and 2 based on shared genomic segments. We found high correlations $(\geq 0.83)$ between the pedigree and genomic relationship measures. The mating results showed that it was possible to reduce the different genetic relationships between parents with minimal effect on genetic level. Including the cost of known recessive genetic defects eliminated expression of genetic defects. It was possible to reduce genomic relationships between parents with pedigree measures, but it was best done with genomic measures. Linear programming maximized the economic score for all herds studied within seconds, which means that it is suitable for implementation in mating software to be used by advisors and farmers.

Key words: genomic relationships, pedigree relationships, mating program, linear programming

\section{INTRODUCTION}

Mating programs are an important support tool for livestock breeders, helping them to identify the best parental matings to maximize genetic level and avoid

\footnotetext{
Received June 10, 2021.

Accepted September 8, 2021.

*Corresponding author: christian.bengtsson@slu.se or chben@ vikinggenetics.com
}

mating between closely related individuals, preventing excessive inbreeding (Carthy et al., 2019; Bérodier et al., 2021). New genetic insights at single nucleotide level can be used in mating programs. Single nucleotide polymorphism markers can give information about major genes and genetic defects. Minimizing the probability of obtaining offspring homozygous for a lethal recessive genetic defect is of economic importance for farmers (Pryce et al., 2012). Further, the EFFAB (European Forum of Farm Animal Breeders, Brussels, Belgium) code of good practice states that breeding organizations should improve health and welfare by reducing the incidence of genetic defects (EFFAB, 2020).

SNP markers also offer the possibility to reduce genomic relationships between parents when making mating plans. Various methods have been proposed for calculation of genomic relationships, including SNP-bySNP relationships as described by, for example, VanRaden (2008). Further, methods using shared genomic segments, as described by, for example, de Cara et al. (2013), aim to reduce the number of runs of homozygosity $(\mathbf{R O H})$ in the offspring. Genomic estimates of relationships are suggested to be more accurate than pedigree information because they do not rely on pedigree completeness or correctness (Pryce et al., 2012; Sun et al., 2013; Carthy et al., 2019) and also because pedigree relationships incorrectly assume infinite, unlinked loci (Hill and Weir, 2011). Furthermore, genomic estimates of relationships can differentiate between animals with the same pedigree relationship that have inherited partly different genetic variants from their parents.

At population level, various genomic relationships have been compared previously with pedigree measures using optimum contribution selection (OCS; Sonesson et al., 2012; Henryon et al., 2019; Meuwissen et al., 2020). Sonesson et al. (2012) concluded that genomic selection needs genomic control of inbreeding. In contrast, using pedigree relationships in OCS, rather than genomic relationships, has been shown to achieve more true genetic gain in the long term (Henryon et al., 2019). Further, Meuwissen et al. (2020) illustrated 
that different relationship matrices are preferred when aiming for maintain heterozygosity or when controlling genetic drift, where the latter prevents genetic defects from drifting to high frequencies and random drift of functional traits.

Several known recessive genetic defects in Nordic Red Dairy Cattle (RDC) are included in the SNP chip currently used for genotyping, and additional genetic defects are included as they are detected. At the beginning of 2020, the carrier status of 6 genetic defects in RDC was automatically provided with the genomic test. Besides reducing genetic relationships, other relevant information (e.g., genetic level, semen cost, the economic impact of recessive genetic defects) has to be considered when making mating plans. An economic score for each potential mating, which combines and weighs all economically relevant information, has been proposed (Pryce et al., 2012; Carthy et al., 2019; Bérodier et al., 2021). Using linear programming to maximize every herd's mean economic score, subject to necessary constraints, is a fast and effective method (Carthy et al., 2019; Bérodier et al., 2021). Further, linear programming has been shown to outperform other mating methods such as sequential mate allocation (Sun et al., 2013; Carthy et al., 2019; Bérodier et al., 2021).

There are several mating programs available in the Nordic countries, but to our knowledge none takes into account genomic relationships to plan matings. In total numbers, RDC is the second most common dairy breed in the Nordic countries Sweden, Finland, and Denmark, with approximately 200,000 cows in the milk recording scheme. Nordic Red Dairy Cattle are a mixture of Swedish Red, Danish Red, and Finnish Ayrshire, and historically also contain genes from Norwegian Red, Canadian Ayrshire, American Brown Swiss, and Red Holstein-Friesian (NAV, 2019). Genotyping of RDC started on a large scale in 2012, with the VikingGenet- ics genotyping project. From 2012 to 2020, more than 100,000 RDC females and 20,000 RDC males were genotyped. Approximately $20 \%$ of the RDC females born in 2019 were genotyped.

Our objective in this study was to investigate the ability of different approaches for mating allocation to maximize expected genetic level, limiting parent relationship and minimizing the probability of expression of genetic defects, in the next generation. We investigated all scenarios at herd level with real data. We used linear programming to optimize different economic scores within each herd, considering genetic level, semen cost, the economic impact of recessive genetic defects, and 5 different measures of relationships (2 pedigree based and 3 genomic based).

\section{MATERIALS AND METHODS}

Breeding values, pedigree data, SNP data, and data on the carrier status of genetic defects were obtained from the Nordic Cattle Genetic Evaluation (NAV, 2019).

\section{Genotype Data}

The SNP information for all genotyped RDC animals born between 2011 and 2020 in Denmark, Finland, and Sweden was available. Nordic Cattle Genetic Evaluation uses the Illumina 50k chip (Illumina Inc.) as the standard for genomic prediction, and genotypes from lower-density chips were imputed by NAV to $50 \mathrm{k}$ with FImpute software (Sargolzaei et al., 2014). From late 2018 onward, most of the animals were genotyped with a EuroG MD beadchip (Borchersen, 2019). In total, the data included genotypes from 149,943 animals $(28,337$ males and 121,606 females).

In RDC, several known recessive genetic defects are segregating (Wu et al., 2020). Genotype information for

Table 1. Known recessive genetic defects, and their effect if homozygous, available with a genomic test for Nordic Red Dairy Cattle

\begin{tabular}{ll}
\hline Recessive genetic defect & Effect if homozygous \\
\hline BTA12 & Early abortion, between the first and fifth month of gestation (Kadri et al., 2014) \\
OMIA 001901-9913 & Stillborn calf (Sahana et al., 2016) \\
BTA23 & Stillborn calf or calf death shortly after birth (Schwarzenbacher et al., 2016) \\
OMIA 001991-9913 & \\
$\begin{array}{l}\text { Brown Swiss haplotype 2(BH2) } \\
\text { OMIA 001939-9913 }\end{array}$ & Early abortion within 100 d of gestation. Inhibited growth if calves are born. PIRM/AH1 are \\
Ptosis intellectual disability, retarded & located very close together and are expected to be the same disease (Guarini et al., 2019). \\
growth, and mortality (PIRM/AH1) & \\
OMIA 001934-9913 & Early abortion within 56 d of gestation (Guarini et al., 2019) \\
Ayrshire haplotype 2 (AH2) & Calves become weak and have problems standing, progressively worsen until they die; seen in wk \\
OMpinal muscular atrophy (SMA) & $1-12$ (Krebs et al., 2007) \\
OMIA 000939-9913 &
\end{tabular}


Table 2. Descriptive statistics on the Nordic Red Dairy Cattle females and bulls selected for mating allocations ${ }^{1}$

\begin{tabular}{lccc}
\hline Trait & Females & Data set BullVG & Data set BullAll \\
\hline Number of animals & 9,841 & 50 & 50 \\
Average Nordic total merit (NTM) & 10.7 & 28.4 & 25.2 \\
Carriers of defect BTA12 (\%) & 14.7 & 12.0 & 14.0 \\
Carriers of defect BTA23 (\%) & 1.1 & 0.0 & 0.0 \\
Carriers of defect BH2 (\%) & 0.3 & 0.0 & 0.0 \\
Carriers of defect PIRM/AH1 (\%) & 1.6 & 0.0 & 0.0 \\
Carriers of defect AH2 (\%) & 1.2 & 0.0 & 0.0 \\
Carriers of defect SMA (\%) & 0.30 & 0.0 & 0.0 \\
\hline
\end{tabular}

${ }^{1}$ BullVG $=50$ genotyped RDC bulls from the Nordic breeding cooperative VikingGenetics; BullAll = 50 genotyped RDC bulls born between January 2017 and August 2019.

a total of 6 genetic defects (Table 1) has been derived by SEGES (Skejby, Denmark) for NAV from SNPs in the EuroG MD beadchip.

\section{Breeding Values}

Genomic breeding values from the NAV evaluation performed in May 2020 were used in this study. The total merit index used was Nordic total merit (NTM), which at the time of this study was composed of 15 subindices, including yield index, youngstock survival, longevity, growth, udder health, udder, feet and legs, frame, hoof health, milkability, daughter fertility, general health, temperament, calving maternal, and calving direct. Nordic total merit is expressed in standardized units with a mean of 0 and a genetic standard deviation of 10 (NAV, 2019).

\section{Data Selection}

Females. We selected 9,841 genotyped females born in Denmark, Finland, or Sweden in 2019 for mating allocations (Table 2). In late 2018, a new SNP array for genotyping was introduced in these countries, which included the 6 known genetic defects listed in Table 1. Hence, 2019 was the first year with complete information about the 6 genetic defects we considered in our mating allocations. All females included belonged to herds with 20 or more genotyped females in 2019. In total, 234 herds were represented, with an average of
42 genotyped females per herd (the smallest number of genotyped females in a herd was 20 and the largest was 244). Descriptive herd statistics on the carrier frequency of the different genetic defects can be found in Table 3.

Bulls. We used 2 data sets on bulls (Table 2), which were potential mates of the 9,841 selected females. The first bull data set (BullVG) included 50 genotyped RDC bulls from the Nordic breeding cooperative VikingGenetics. These bulls were born between January 2017 and August 2019. Since it became possible, RDC bulls have been subjected to additional tests for the 6 genetic defects considered here, enabling us to use older bulls than females in our mating allocations. At VikingGenetics, the program EVA (Berg et al., 2006) is used for OCS using pedigree relationships (Jakob Lykke Voergaard, product manager, VikingRed, VikingGenetics, personal communication, January 11, 2021). The bulls we chose as potential mates in this study were the top available RDC bulls based on the NTM scale for which semen was marketed. There were 32 sires of the bulls in BullVG. In total, 6 of the 50 bulls were carriers of the recessive genetic defect at BTA12. None of the other genetic defects in Table 1 was present in BullVG. The highest-ranked carrier bull of the genetic defect at BTA12 was number 13 on the NTM scale.

The second bull data set (BullAll) also consisted of 50 genotyped RDC bulls born between January 2017 and August 2019. We removed the requirement to use only marketed semen, to eliminate any pre-selection

Table 3. Herd descriptive statistics $(\mathrm{n}=234)$ of the carrier frequency (proportion of heterozygotes) of the 6 known genetic defects in Nordic Red Dairy Cattle ${ }^{1}$

\begin{tabular}{lccccrc}
\hline Heading & BTA12 & BTA23 & BH2 & PIRM/AH1 & AH2 & SMA \\
\hline Mean (\%) & 15.0 & 1.3 & 0.3 & 1.8 & 1.4 & 0.3 \\
Min (\%) & 0.0 & 0.0 & 0.0 & 0.0 & 0.0 & 0.0 \\
Max (\%) & 36.0 & 9.5 & 9.5 & 17.4 & 21.0 & 6.2 \\
First quartile (\%) & 10.2 & 0.0 & 0.0 & 3.0 & 0.0 & 0.0 \\
Third quartile (\%) & 19.2 & 2.2 & 0.0 & 0.0 & 2.0 & 0.0 \\
\hline
\end{tabular}

${ }^{1}$ Mean = mean of all herds carrier frequency; Min = minimum percent of carriers in any herds; Max $=$ maximum percent of carriers in any herds. 
for the breeding program based on bull carrier status. Further, we selected 50 bulls in a row on the NTM ranking so that a carrier of genetic defect at BTA12 would be ranked number 3 and that the bull data set in total would contain a higher carrier frequency. There were 33 sires of the 50 bulls in BullAll. In BullAll, 7 bulls were carriers of genetic defect at BTA12 and one was a carrier of genetic defect at BTA23 (Table 2). The carrier of genetic defect at BTA23 was number 19 on the NTM ranking.

\section{Relationship Measures}

Pedigree Relationships. We used 2 different pedigree relationship coefficients. To reflect the current Nordic mating programs, which use limited number of generations when calculating relationships, the first relationship coefficient traced the pedigree 3 generations back from the parents of the potential mating $\left(\mathbf{a}_{3 \mathrm{Gen}}\right)$. The second pedigree relationship coefficient was based on all available pedigree information $\left(\mathbf{a}_{\text {AllGen }}\right)$. The discrete generation equivalent (Woolliams and Mäntysaari, 1995) for the mated animals was 18.0 and the equivalent complete generations (Maignel et al., 1996) was 12.6. The 5 -generation pedigree completeness for genotyped animals was $99.4 \%$.

The pedigree file contained 48,434,951 animals. For most cases, the pedigree for genotyped animals was already corrected for mismatches by NAV. We found only 7 genotyped animals with mismatching parents, and they were excluded from further analyses. The pedigree relationship coefficients were estimated in RelaX2 software (Strandén and Vuori, 2006), which uses an algorithm modified from Meuwissen and Luo (1992).

Genomic Relationships. We used 3 different genomic relationship coefficients, one SNP-by-SNP genomic relationship and 2 based on shared genomic segments. The SNP-by-SNP genomic relationship coefficient $\left(\mathbf{g}_{\mathbf{S N P}}\right)$ between animals $i$ and $j$ was calculated according to VanRaden (2008):

$$
g_{S N P_{i j}}=\frac{\sum_{m}\left(x_{i m}-2 p_{m}\right) \times\left(x_{j m}-2 p_{m}\right)}{2 \sum_{m} p_{m}\left(1-p_{m}\right)},
$$

where $x_{i m}$ and $x_{j m}$ are the genotype scores of animal $i$ and animal $j$ at marker $m$, coded: $0=$ homozygote, 1 $=$ heterozygote, and $2=$ alternative homozygote, and $p_{m}$ is the frequency of the alternative allele of marker $m$ in the founder population. Because we did not know the founder population frequency, we instead used the allele frequency of all 149,943 genotyped RDC animals available for this study, as is common practice for ge- nomic evaluation (Wang et al., 2014). We used the software SNP1101 to calculate the SNP-by-SNP genomic relationship coefficients (Sargolzaei, 2014).

The 2 genomic relationship coefficients based on shared genomic segments were calculated following de Cara et al. (2013):

$$
g_{S E G_{i j}}=\frac{\sum_{k} \sum_{a i=1}^{2} \sum_{b j=1}^{2}\left[L_{S E G k}\left(a_{i} b_{j}\right)\right]}{2 L_{A U T O}},
$$

where $L_{S E G k}$ is the length (in base pairs) of the $k$ th shared segment measured over homolog $a$ of animal $i$ and homolog $b$ of animal $j$, and $L_{A U T O}$ is the total length of the autosomes covered by the SNP in base pairs.

The 2 segment-based genomic relationship coefficients were based on different minimum lengths of segments: $1 \mathrm{cM}\left(\mathbf{g}_{\mathrm{SEG} 1}\right)$ and $4 \mathrm{cM}$ ( $\left.\mathbf{g}_{\mathrm{SEG} 4}\right)$, assuming 1 $\mathrm{cM}=1,000,000 \mathrm{bp}$ (Gautier et al., 2007). The lengths of segments were chosen to represent short and long segments, similarly to other studies (Zhang et al., 2015; Forutan et al., 2018; Makanjuola et al., 2020; Martikainen et al., 2020). Phasing of genotypes was done in Beagle 4.1 with default settings (Browning and Browning, 2007), and segments of minimum desired length were extracted in RefineIBD with the default setting except for the logarithm of the odds (LOD) score (base $10 \log$ of the likelihood ratio), where we used LOD = 0.1 (Browning and Browning, 2013). The LOD score is used to prune out shared segments that are not common in the population. Hence, default LOD $=3.0$ in RefineIBD was considered too high for our purposes, as in a recent study (Olsen et al., 2020).

\section{Economic Score}

For each potential mating between female $i$ and bull $j$, we calculated an economic score as done by Bérodier et al. (2021) and Pryce et al. (2012):

$$
\begin{aligned}
& \text { Score }_{i j}= \\
& \left(\frac{N T M_{i}+N T M_{j}}{2}+\lambda F_{i j}\right) \times \operatorname{prob}(\text { Fem }) \\
& -\sum_{r=1}^{n_{r}} p(a a)_{r} \times v_{r}-\text { semen cost, }
\end{aligned}
$$

where $N T M_{i}$ and $N T M_{j}$ are the value of Nordic total merit units in euros $(€)$ for female $i$ and bull $j, \lambda$ is the economic consequence of a $1 \%$ increase in inbreeding, $F_{i j}$ is the pedigree or genomic based co-ancestry (relationship/2), $\operatorname{prob}(\mathrm{Fem})$ is the probability of producing a female conceptus, $n_{r}$ is the number of recessive 
genetic defects considered, $p(a a)_{r}$ is the probability of expression of a genetic defect $r, v_{r}$ is the economic cost associated with the recessive genetic defect $r$, and semen cost is the average amount $(€)$ spent on semen for a pregnancy.

The value of 1 index unit of NTM was approximated to be $€ 24.8$, based on the value per NTM unit and year (€9.2) the average and production lifetime $(2.7$ yr; Fikse and Kargo, 2020). We only considered sexed semen and assumed a 0.9 probability of producing a female conceptus, which is the minimum expected sexing rate for most sexing technologies (Burnell, 2019). Sexed semen is gaining popularity in the Nordic countries and is combined with the use of beef semen to get the number of heifers needed for the next generation. It is expected that most of the semen sold by VikingGenetics in future will be sexed dairy semen and beef semen (Jakob Lykke Voergaard, product manager, VikingRed, VikingGenetics, personal communication, January 11, 2021).

The economic consequence of a $1 \%$ increase in inbreeding was set to $€ 24.8$. The current version of the Swedish mating program "Genvägen" uses a penalty of 1 NTM unit per $1 \%$ increase in inbreeding, which would mean $€ 24.8$ (Lina Baudin, expert in breeding routines, Växa Sverige, personal communication, March 5, 2021). To our knowledge, no such values have been calculated specifically for the RDC breed, and therefore in a sensitivity analysis we set the economic consequence of a $1 \%$ increase in inbreeding to $€ 10.0$, €24.8, or $€ 40.0$. The analysis was performed with BullVG and scenarios maximizing economic scores, including all available information and a maximum of $5 \%$ females per bull and herd.

The costs associated with genetic defects were based on economic effects of health disorders estimated by Oskarsson and Engelbrekts (2015) and the economic assumptions behind the NTM (Sørensen et al., 2018). We assumed the cost of an early abortion (genetic defect at BTA12, PIRM/AH1, AH2) to be $€ 80$, based on the resulting longer calving interval (€30-€40/mo) and the cost of extra insemination(s) (€30). We assumed the cost of a later abortion or an early calf death to be $€ 160$ (genetic defect SMA, BH2, and at BTA23).

We used the prices for sexed semen set by VikingGenetics in 2020, where a semen dose for a bull with a NTM of 30 or more cost $€ 26$, with a NTM of 25 to 30 cost $€ 22.5$, and with a NTM of 20 to 25 cost $€ 19$ (Jakob Lykke Voergaard, product manager, VikingRed, VikingGenetics, personal communication, January 11, 2021). We multiplied the semen price by 1.8 , which is the average number of inseminations needed for a pregnancy in RDC (Sørensen et al., 2018).

\section{Mating Scenarios}

In addition to the economic scores that included all available information described above, we investigated mating scenarios without the penalty for genetic defects. In addition, we investigated scenarios that only aimed to reduce the genetic relationships. Detailed information about the mating scenarios can be found in Table 4.

\section{Mate Allocation}

Mate allocation was programmed in $\mathrm{R}$ version 3.6.3 ( $\mathrm{R}$ Core Team, 2020). Linear programming optimization was performed with the 'Lp_solve' package in $\mathrm{R}$ (Berkelaar et al., 2020). The mating $\mathrm{R}$ script was provided by Bérodier et al. (2021). The R script set up constraints that were considered in the linear programming optimization. We used the constraints: one mating per female and a threshold percentage for the maximum number of females per bull and herd, for which we evaluated 2 different levels, $5 \%$ and $10 \%$, similarly to Bérodier et al. (2021). The threshold for the number of females per bull and herd was in line with current recommendations given by Swedish breeding advisors.

The planned matings achieved from each scenario were compared by (1) average NTM; (2) average genetic relationships $\left(\mathrm{a}_{3 \mathrm{Gen}}, \mathrm{a}_{\mathrm{AllGen}}, \mathrm{g}_{\mathrm{SNP}}, \mathrm{g}_{\mathrm{SEG} 1}, \mathrm{~g}_{\mathrm{SEG} 4}\right) ;(3)$ the probability of expression of genetic defects, including genetic defect at BTA12, using bull set BullVG, and including genetic defects at BTA12 and BTA23 using bull set BullAll; (4) the average cost of semen for a pregnancy, calculated in the same way as in the economic score; (5) the total number of bulls used; (6) the number of bulls used to the maximum number of doses based on the threshold ( $5 \%$ and 10\%) of females per bull and herd; (7) average pedigree relationship among all planned matings, calculated similarly to $\mathrm{a}_{\mathrm{AllGen}}$; and (8) predicted carrier frequency of genetic defect at BTA12 using BullVG, and predicted carrier frequency of genetic defects at BTA12 and BTA23 using BullAll, calculated as $50 \%$ of the cases when a parent was a carrier divided by the total number of matings. The predicted carrier frequency in the next generation did not include homozygotes for the genetic defects, which were included in the probability of expression of genetic defects.

\section{Statistical Analysis}

SAS software version 9.4 (SAS Institute Inc.) and $\mathrm{R}$ version 3.6.3 ( $\mathrm{R}$ Core Team, 2020) were used for statistical analysis. 


\section{RESULTS}

All results are presented for the selected females and bulls in BullVG, unless otherwise specified.

\section{Genetic Relationship Coefficients}

The mean value of the relationship coefficients between all possible combinations of females and males ranged from 0.009 to 0.188 , and the standard deviation ranged from 0.042 to 0.047 (Table 5). The correlations between the genetic relationship coefficients were all 0.83 or higher. The strongest correlation was between $\mathrm{a}_{\text {AllGen }}$ and $\mathrm{a}_{3 \mathrm{Gen}}(\mathrm{r}=0.99)$, and the second strongest was between $g_{\mathrm{SEG} 1}$ and $\mathrm{g}_{\mathrm{SEG} 4}(\mathrm{r}=0.98)$. The strongest correlation between pedigree and genomic relationships was between $\mathrm{a}_{\mathrm{AllGen}}$ and $\mathrm{g}_{\mathrm{SEG} 4}(\mathrm{r}=0.88$; Table 6$)$. The coefficients of regression on $\mathrm{a}_{\text {AllGen }}$ were close to 1 , highest for $\mathrm{a}_{3 \mathrm{Gen}}$ and $\mathrm{g}_{\mathrm{SNP}}$ and somewhat lower for $\mathrm{g}_{\mathrm{SEG} 1}$ and $\mathrm{g}_{\mathrm{SEG} 4}$ (Figure 1).

Table 4. Description of the 15 different mating scenarios considered

Economic score includes

\begin{tabular}{|c|c|c|c|c|c|c|}
\hline Scenario $^{1}$ & $\begin{array}{l}\text { Nordic total } \\
\text { merit, NTM }\end{array}$ & Relationship $^{2}$ & $\begin{array}{l}\text { Genetic defect } \\
\text { value }\end{array}$ & $\begin{array}{l}\text { Sexed } \\
\text { semen }\end{array}$ & $\begin{array}{l}\text { Semen } \\
\text { cost }\end{array}$ & $\begin{array}{l}\text { Linear programming } \\
\text { objective }^{3}\end{array}$ \\
\hline MaxNTM & Yes & No & No & Yes & Yes & $\operatorname{Max}$ \\
\hline $3 \mathrm{Gen}$ & Yes & $a_{3 \mathrm{Gen}}$ & Yes & Yes & Yes & $\operatorname{Max}$ \\
\hline GSNP & Yes & $\mathrm{g}_{\mathrm{SNP}}$ & Yes & Yes & Yes & Max \\
\hline GSEG1 & Yes & $\mathrm{g}_{\mathrm{SEG} 1}$ & Yes & Yes & Yes & Max \\
\hline GSEG4 & Yes & $\mathrm{g}_{\mathrm{SEG} 4}$ & Yes & Yes & Yes & $\operatorname{Max}$ \\
\hline GSNP_NoDefect & Yes & $\mathrm{g}_{\mathrm{SNP}}$ & No & Yes & Yes & Max \\
\hline GSEG1_NoDefect & Yes & $\mathrm{g}_{\mathrm{SEG} 1}$ & No & Yes & Yes & Max \\
\hline GSEG4_NoDefect & Yes & $\mathrm{g}_{\mathrm{SEG} 4}$ & No & Yes & Yes & Max \\
\hline 3Gen_Min & No & $\mathrm{a}_{3 \mathrm{Gen}}$ & No & Yes & No & Min \\
\hline AllGen_Min & No & $\mathrm{a}_{\mathrm{AllG}}$ & No & Yes & No & Min \\
\hline GSNP_Min & No & $\mathrm{g}_{\mathrm{SNP}}$ & No & Yes & No & Min \\
\hline GSEG1_Min & No & $\mathrm{g}_{\mathrm{SEG} 1}$ & No & Yes & No & Min \\
\hline
\end{tabular}

${ }^{1}$ MaxNTM: mating scenario where mates were selected based on maximizing an economic score including NTM, sexed semen, and semen cost. $3 \mathrm{Gen}$ : mating scenario where mates were selected based on maximizing an economic score including NTM, sexed semen, semen cost, a pedigree relationship including 3 generations of ancestors $\left(\mathrm{a}_{3 \mathrm{Gen}}\right)$, and penalty for genetic defects. AllGen: mating scenario where mates were selected based on maximizing an economic score including NTM, sexed semen, semen cost, a pedigree relationship including all available ancestors $\left(\mathrm{a}_{\mathrm{All} G e n}\right)$, and penalty for genetic defects. GSNP: mating scenario where mates were selected based on maximizing an economic score including NTM, sexed semen, semen cost, a genomic relationship calculated according to VanRaden (2008) ( $\mathrm{g}_{\mathrm{SNP}}$ ), and penalty for genetic defects. GSEG1: mating scenario where mates were selected based on maximizing an economic score including NTM, sexed semen, semen cost, a genomic relationship based on shared genomic segment calculated according to de Cara et al. (2013) with a minimum genomic segment length of $1 \mathrm{cM}$ $\left(\mathrm{g}_{\mathrm{SEG} 1}\right)$, and penalty for genetic defects. GSEG4: mating scenario where mates were selected based on maximizing an economic score including NTM, sexed semen, semen cost, and a genomic relationship based on shared genomic segment calculated according to de Cara et al. (2013) with a minimum genomic segment length of $4 \mathrm{cM}\left(\mathrm{g}_{\mathrm{SEG} 4}\right)$, and penalty for genetic defects. 3Gen_NoDefect: mating scenario where mates were selected based on maximizing an economic score including NTM, sexed semen, semen cost, and a pedigree relationship including 3 generations of ancestors $\left(\mathrm{a}_{3 \mathrm{Gen}}\right)$. AllGen_NoDefect: mating scenario where mates were selected based on maximizing an economic score including NTM, sexed semen, semen cost, and a pedigree relationship including all available ancestors $\left(\mathrm{a}_{\text {AllGen }}\right)$. GSNP_NoDefect: mating scenario where mates were selected based on maximizing an economic score including NTM, sexed semen, semen cost, and a genomic relationship calculated according to VanRaden (2008) $\left(\mathrm{g}_{\mathrm{SNP}}\right)$. GSEG1_NoDefect: mating scenario where mates were selected based on maximizing an economic score including NTM, sexed semen, semen cost, and a genomic relationship based on shared genomic segment calculated according to de Cara et al. (2013) with a minimum genomic segment length of $1 \mathrm{cM}\left(\mathrm{g}_{\mathrm{SEG} 1}\right)$. GSEG4_NoDefect: mating scenario where mates were selected based on maximizing an economic score including NTM, sexed semen, semen cost, and a genomic relationship based on shared genomic segment calculated according to de Cara et al. (2013) with a minimum genomic segment length of $4 \mathrm{cM}\left(\mathrm{g}_{\mathrm{SEG} 4}\right)$. 3Gen_Min: mating scenario where mates were selected based on minimizing an economic score including a pedigree relationship including 3 generations of ancestors. AllGen_Min: mating scenario where mates were selected based on minimizing an economic score including a pedigree relationship including all available ancestors. GSNP_Min: mating scenario where mates were selected based on minimizing an economic score including a genomic relationship calculated according to VanRaden (2008). GSEG1_Min: mating scenario where mates were selected based on minimizing an economic score, including a genomic relationship based on shared genomic segment calculated according to de Cara et al. (2013) with a minimum genomic segment length of 1 cM. GSEG4_Min: mating scenario where mates were selected based on minimizing an economic score including a genomic relationship based on shared genomic segment calculated according to de Cara et al. (2013) with a minimum genomic segment length of $4 \mathrm{cM}$.

${ }^{2} \mathrm{a}_{3 \mathrm{Gen}}=$ pedigree relationships using 3 generations of ancestors; $\mathrm{a}_{\mathrm{AllGen}}=$ pedigree relationships using all available pedigree information; $\mathrm{g}_{\mathrm{SNP}}=$ genomic relationship calculated according to VanRaden $(2008) ; \mathrm{g}_{\mathrm{SEG} 1}\left(\mathrm{~g}_{\mathrm{SEG} 4}\right)=$ genomic segment-based relationship according to de Cara et al. (2013) with a minimum segment length of 1 (4) cM.

${ }^{3}$ The objective of linear programming is to maximize (Max) or minimize (Min) the economic score. 
Table 5. Descriptive statistics on relationships [mean, SD, minimum value (Min), and maximum value (Max)] between all possible combinations of 9,841 females and 50 bulls $^{1}$

\begin{tabular}{lcccc}
\hline Relationship & Mean & SD & Min & Max \\
\hline $\mathrm{a}_{3 \mathrm{Gen}}$ & 0.028 & 0.042 & 0 & 0.648 \\
$\mathrm{a}_{\text {AllGen }}$ & 0.066 & 0.042 & 0.003 & 0.667 \\
$\mathrm{~g}_{\mathrm{SNP}}$ & 0.009 & 0.047 & -0.095 & 0.673 \\
$\mathrm{~g}_{\text {SEG1 }}$ & 0.188 & 0.046 & 0.038 & 0.789 \\
g $_{\text {SEG4 }}$ & 0.115 & 0.045 & 0.005 & 0.727 \\
\hline
\end{tabular}

${ }^{1} \mathrm{a}_{3 \mathrm{Gen}}=$ pedigree relationships using 3 generations of ancestors; $\mathrm{a}_{\mathrm{AllGen}}$ $=$ pedigree relationships using all available pedigree information; $\mathrm{g}_{\mathrm{SNP}}$ = genomic relationship calculated according to VanRaden (2008); $\mathrm{g}_{\mathrm{SEG} 1}\left(\mathrm{~g}_{\mathrm{SEG} 4}\right)=$ genomic segment-based relationship according to de Cara et al. (2013) with a minimum segment length of 1 (4) cM.

\section{Mate Allocation}

Using BullVG. It was possible to maximize economic score with limited impact on the average NTM level (Table 7). Including the cost of the known recessive genetic defect (at BTA12) when optimizing mating strategies eliminated the risk of expression of the genetic defect, regardless of which genetic relationship was used. In MaxNTM (mating scenario where mates were selected based on maximizing an economic
Table 6. Correlations between the different relationship coefficients for all possible combinations of 9,841 females and 50 bulls $^{1}$

\begin{tabular}{lccccc}
\hline Relationship & $\mathrm{a}_{3 \mathrm{Gen}}$ & $\mathrm{a}_{\text {AllGen }}$ & $\mathrm{g}_{\mathrm{SNP}}$ & $\mathrm{g}_{\mathrm{SEG} 1}$ & $\mathrm{~g}_{\mathrm{SEG} 4}$ \\
\hline $\mathrm{a}_{3 \mathrm{Gen}}$ & 1 & 0.99 & 0.88 & 0.83 & 0.87 \\
$\mathrm{a}_{\text {AllGen }}$ & & 1 & 0.88 & 0.85 & 0.88 \\
$\mathrm{~g}_{\mathrm{SNP}}$ & & & 1 & 0.9 & 0.93 \\
g $_{\text {SEG1 }}$ & & & & 1 & 0.98 \\
\hline
\end{tabular}

${ }^{1} \mathrm{a}_{3 \mathrm{Gen}}=$ pedigree relationships using 3 generations of ancestors; $\mathrm{a}_{\mathrm{AllGen}}$ $=$ pedigree relationships using all available pedigree information, $g_{\mathrm{SNP}}$ = genomic relationship calculated according to VanRaden (2008); $\mathrm{g}_{\mathrm{SEG} 1}\left(\mathrm{~g}_{\mathrm{SEG} 4}\right)=$ genomic segment-based relationship according to de Cara et al. (2013) with a minimum segment length of 1 (4) cM.

score including NTM, sexed semen, and semen cost), the NTM level improved compared with Random (all possible combinations of 9,841 females and 50 bulls), but it resulted in higher average genetic relationship coefficients than Random and did not reduce the probability of expression of genetic defects.

Including a genomic relationship in the economic score also kept the other genomic relationship averages at a low level. For example, with the constraint 5\% females per bull and herd, including $\mathrm{g}_{\mathrm{SNP}}$ in the objective function (scenario GSNP) resulted in a g gef $1_{\text {of }}$ a



C

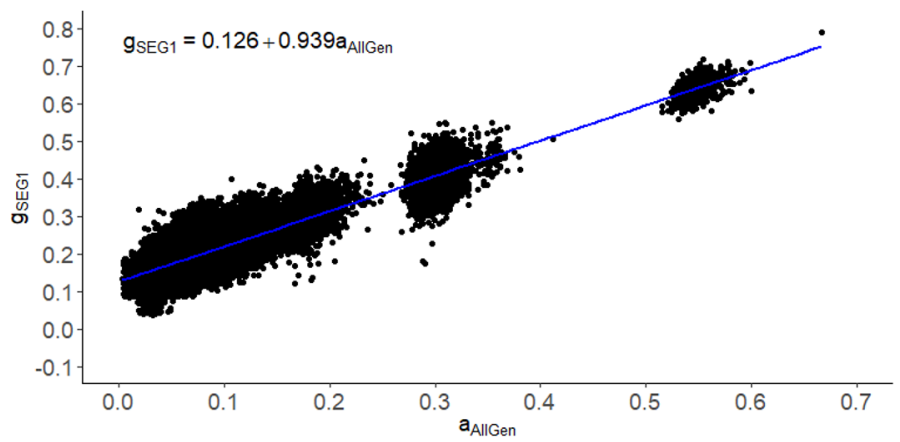

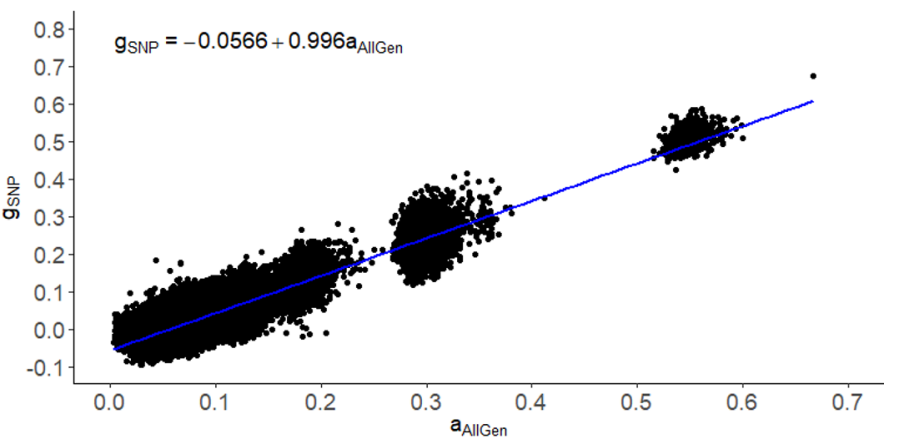



Figure 1. (a) Relationship coefficients estimated from pedigree data with 3 generations of ancestors $\left(\mathrm{a}_{3 \mathrm{Gen}}\right)$, (b) relationship coefficients estimated from SNP data ( $\mathrm{g}_{\mathrm{SNP}}$; VanRaden, 2008), (c) relationship coefficients estimated from shared genomic segments with a minimum segment length of $1 \mathrm{cM}\left(\mathrm{g}_{\mathrm{SEG} 1}\right)$, and $(\mathrm{d})$ minimum length of $4 \mathrm{cM}$ ( $\mathrm{g}_{\mathrm{SEG} 4}$; de Cara et al., 2013), all plotted against relationship coefficients estimated from pedigree data using all available ancestors $\left(\mathrm{a}_{\mathrm{AllGen}}\right)$. The diagrams include relationships for all possible combinations of 9,841 Nordic Red Dairy Cattle females and 50 bulls. 
Bengtsson et al.: MATING ALLOCATIONS USING GENOMIC INFORMATION

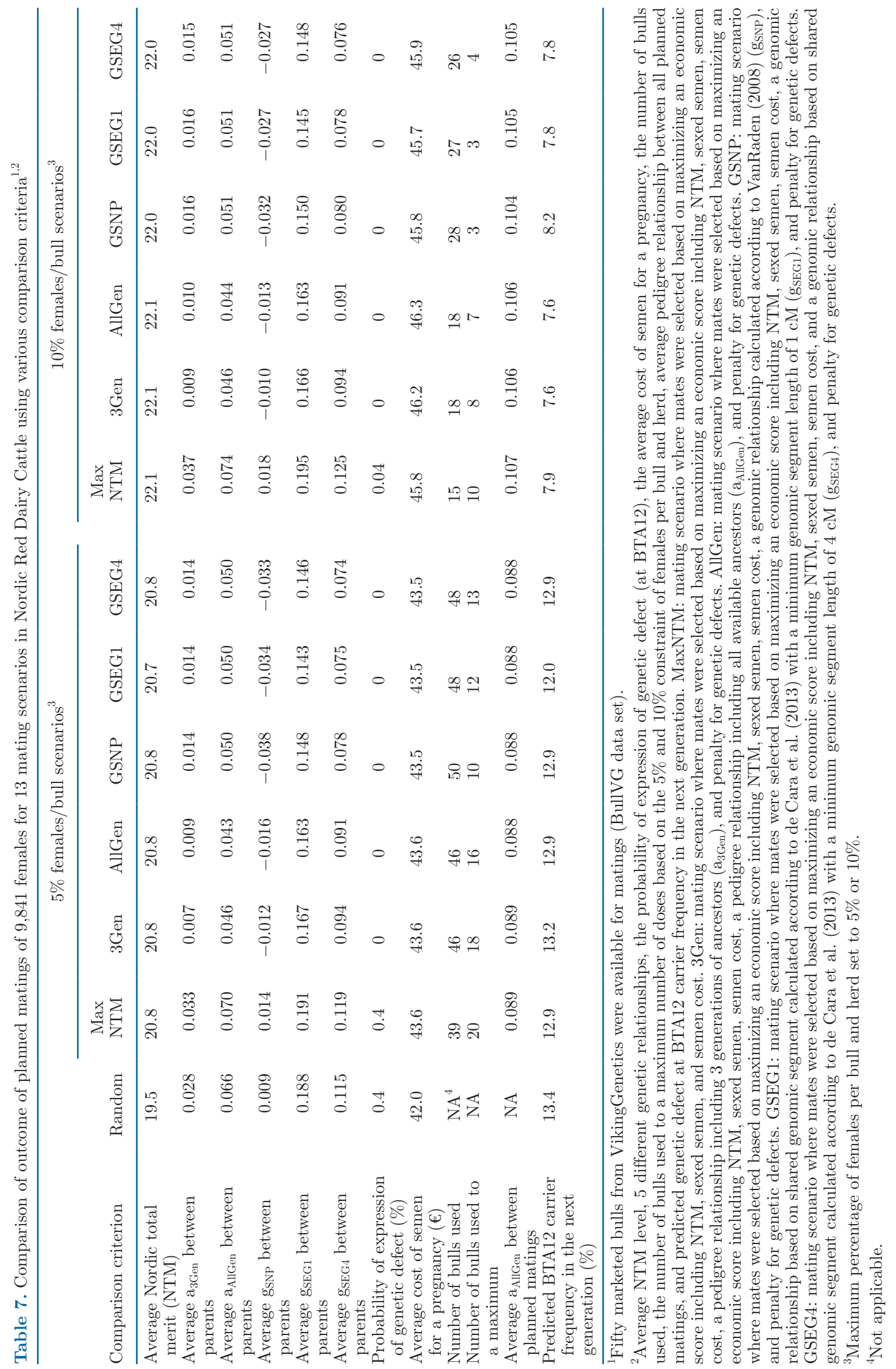


0.148, compared with 0.143 with GSEG1 (Table 7). Using the pedigree relationships also reduced the genomic relationships compared with Random and MaxNTM, but not as much as using genomic relationships in the objective function. Considering the example with the constraint $5 \%$ females per bull and herd, and including $g_{S N P}$ in the objective function (scenario GSNP), the pedigree relationship scenarios resulted in a $\mathrm{g}_{\mathrm{SEG} 1}$ of 0.167 for $3 \mathrm{Gen}$ and 0.163 for AllGen. There were only minor differences between the scenarios with genomic relationships in their ability to reduce pedigree relationships. Including pedigree relationships in the economic scores consistently reduced pedigree relationships more than genomic relationships. For example, all scenarios optimizing genomic relationships resulted in $\mathrm{a}_{\mathrm{AllG}}$ of 0.050 , AllGen resulted in $\mathrm{a}_{\text {AllGen }}$ of 0.043 , and $3 \mathrm{Gen}$ resulted in $\mathrm{a}_{\text {AllGen }}$ of 0.046 (Table 7).

Using BullAll. For the bull set BullAll, including the costs of the known recessive genetic defects (at BTA12 and BTA23) when optimizing mating strategies entirely eliminated the risk of expression of a genetic defect, regardless of which genetic relationship was used in the objective function (Table 8).

Bull Usage. The number of bulls used in the scenarios considering genomic relationships was always higher than in the scenarios considering pedigree relationships. Furthermore, fewer bulls were used for the maximum number of permitted inseminations considering genomic relationships compared with scenarios considering pedigree relationships with the same constraints. Minor differences were observed in the average pedigree relationship between all planned matings using the same threshold for females per bull and herd.

\section{Predicted Carrier Frequency in the Next Generation}

The predicted carrier frequency in the next generation was half the carrier frequencies in Table 2 for the genetic defects not present in bull set BullVG (at BTA23, BH2, PIRM/AH1, AH2, SMA) and bull set BullAll (BH2, PIRM/AH1, AH2, SMA). Further, the predicted carrier frequencies of known genetic defects in the next generation depended on the proportion of carrier bull used. Using a maximum of $10 \%$ females per bull and herd resulted in considerably lower carrier frequencies in the next generation (Table 7). In this case, the best carrier bull was ranked number 13 on the NTM scale and that bull was rarely chosen in any of the mating allocations. However, when using a maximum constraint of $5 \%$ females per bull and herd, the predicted carrier frequency in the next generation was higher than with a maximum constraint of $10 \%$ females per bull and herd. The bull ranked number 13 and the other lower-ranked bulls on the NTM scale were then required to be used due to the constraint. When using bull set BullAll, more carrier bulls were ranked high on the NTM scale. Hence, it resulted in higher predicted carrier frequency in the next generation as a consequence of carrier bulls being selected more often (Table 8) than when using bull set BullVG (Table 7).

\section{Alternative Scenarios}

Results for scenarios excluding genetic defects from the objective function showed a probability of expression of genetic defect without the penalty for defects in the economic score (Table 9). Including g $_{\mathrm{SEG} 1}$ resulted in the lowest probability of expression of genetic defects. There were only minor changes for the other result parameters compared with when the penalty was included.

Results for scenarios minimizing parents' genetic relationships showed a lower average NTM level than the other scenarios, because they were not optimized with respect to NTM (Table 10). Furthermore, the average $\mathrm{a}_{\mathrm{AllGen}}$ between planned matings was improved (e.g., 0.083 in AllGen_Min to 0.089 in MaxNTM). In MaxNTM, the average $a_{\text {AllGen }}$ relationship was 0.070 (Table 9). Compared with scenarios maximizing economic scores, including all information except the defect penalty (Table 9), the genetic relationships could be reduced slightly more. For example, in AllGen_NoDefect, the a allGen relationship was 0.043 (Table 9) and in AllGen_Min it was 0.040 (Table 10). Similarly, in GSNP_NoDefect $\mathrm{g}_{\mathrm{SNP}}$ was -0.038 and in GSNP_Min it was -0.044. Further, in the scenarios aimed at only minimizing the parents' genetic relationship, we observed a probability of expression of a genetic defect. AllGen_Min and GSEG4_Min resulted in a $0.2 \%$ probability of expression of a genetic defect and GSEG1_Min in $0.1 \%$ probability, compared with $0.4 \%$ probability in Random and MaxNTM.

\section{Effect of Constraints Used in Mate Allocation}

Changing the maximum number of females per bull and herd from $5 \%$ to $10 \%$ resulted in a higher NTM, and the increase was greater for BullVG (1.2-1.4 NTM units) than for BullAll (0-0.2 NTM units; Table 7-8), owing to more variation in NTM level in BullVG than in BullAll. Lower variation in NTM level led to genetic relationships being more decisive in mating optimization, which in turn led to fewer bulls being used to their maximum number of inseminations based on the constraints $5 \%$ and $10 \%$ females per bull and herd. For example, in $3 \mathrm{Gen}$, using the constraint $5 \%$ females per 


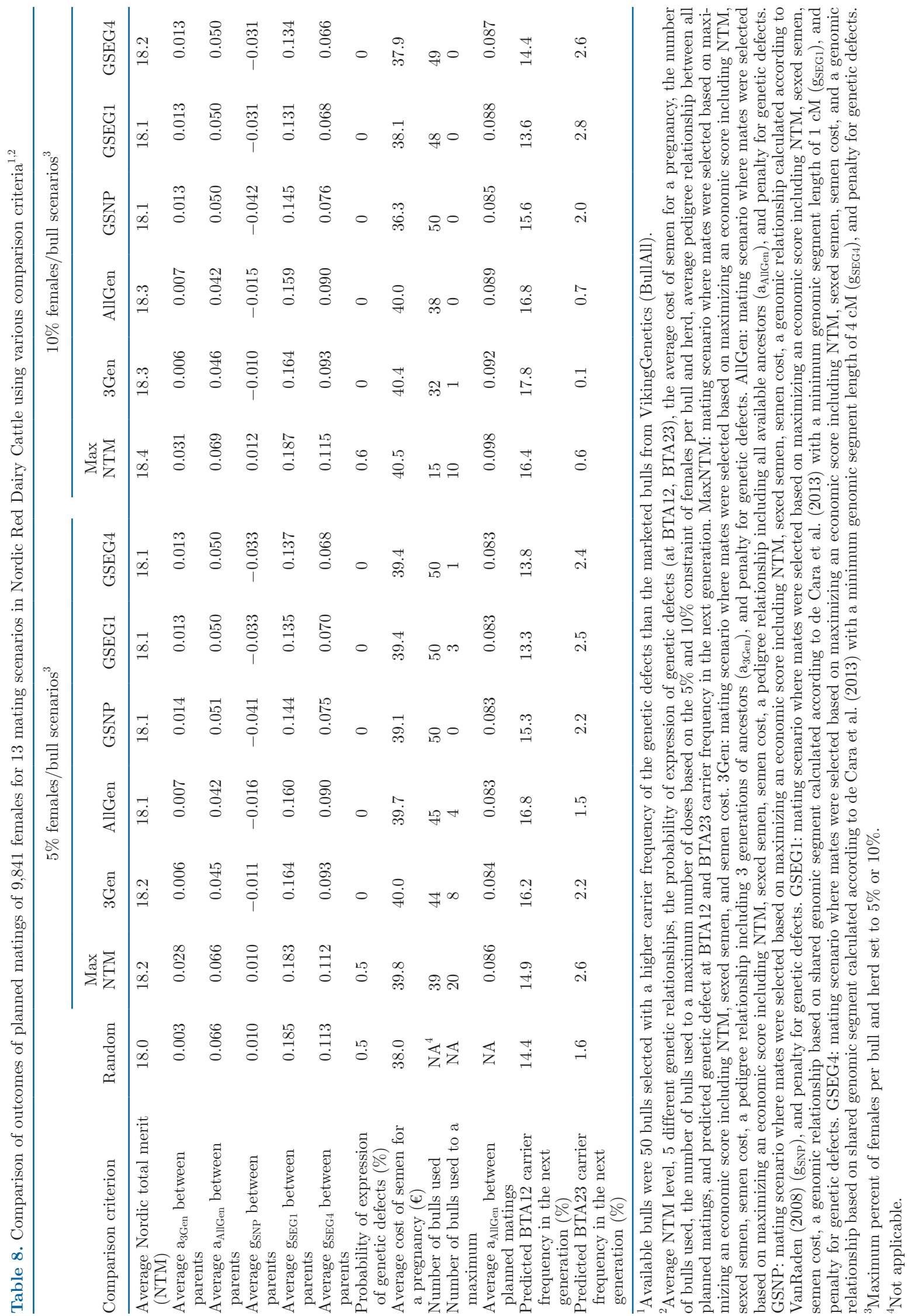


Table 9. Comparison of outcome of planned matings of 9,841 females for 6 mating scenarios in Nordic Red Dairy Cattle using various comparison criteria $^{1,2}$

\begin{tabular}{|c|c|c|c|c|c|c|}
\hline \multirow[b]{2}{*}{ Comparison criterion } & \multirow[b]{2}{*}{$\begin{array}{l}\text { Max } \\
\text { NTM }\end{array}$} & \multicolumn{5}{|c|}{ Scenarios without penalty for defects } \\
\hline & & $\begin{array}{l}\text { 3Gen_No } \\
\text { Defect }\end{array}$ & $\begin{array}{l}\text { AllGen_No } \\
\text { Defect }\end{array}$ & $\begin{array}{l}\text { GSNP_No } \\
\text { Defect }\end{array}$ & $\begin{array}{l}\text { GSEG1_No } \\
\text { Defect }\end{array}$ & $\begin{array}{l}\text { GSEG4_No } \\
\text { Defect }\end{array}$ \\
\hline Average $a_{3 \mathrm{Gen}}$ between parents & 0.033 & 0.007 & 0.009 & 0.014 & 0.014 & 0.014 \\
\hline Average $a_{\text {AllGen }}$ between parents & 0.070 & 0.046 & 0.043 & 0.050 & 0.050 & 0.050 \\
\hline Average $g_{S N P}$ between parents & 0.014 & -0.012 & -0.016 & -0.038 & -0.034 & -0.033 \\
\hline Probability of expression of genetic defect (\%) & 0.4 & 0.4 & 0.4 & 0.4 & 0.2 & 0.3 \\
\hline Average cost of semen for a pregnancy $(€)$ & 43.6 & 43.6 & 43.6 & 43.5 & 43.5 & 43.5 \\
\hline Number of bulls used & 39 & 46 & 45 & 50 & 48 & 47 \\
\hline Number of bulls used to a maximum & 20 & 18 & 16 & 10 & 12 & 13 \\
\hline Average $a_{\text {AllGen }}$ between planned matings & 0.089 & 0.089 & 0.088 & 0.088 & 0.088 & 0.088 \\
\hline $\begin{array}{l}\text { Predicted BTA12 carrier frequency in the } \\
\text { next generation }(\%)\end{array}$ & 12.9 & 13.0 & 12.8 & 13.1 & 12.6 & 12.8 \\
\hline
\end{tabular}

${ }^{1}$ Fifty marketed bulls from VikingGenetics were available for matings (BullVG). Maximum percentage of females per bull and herd set to $5 \%$.

${ }^{2}$ Average NTM level, 5 different genetic relationships, the probability of expression of genetic defect (at BTA12), the average cost of semen for a pregnancy, the number of bulls used, the number of bulls used to a maximum number of doses based on the $5 \%$ of females per bull and herd, average pedigree relationship between all planned matings, and predicted genetic defect at BTA12 carrier frequency in the next generation. MaxNTM: mating scenario where mates were selected based on maximizing an economic score including NTM, sexed semen, and semen cost. 3Gen_NoDefect: mating scenario where mates were selected based on maximizing an economic score including NTM, sexed semen, semen cost, and a pedigree relationship including 3 generations of ancestors $\left(\mathrm{a}_{3 \mathrm{Gen}}\right)$. AllGen_NoDefect: mating scenario where mates were selected based on maximizing an economic score including NTM, sexed semen, semen cost, and a pedigree relationship including all available ancestors ( $\mathrm{a}_{\mathrm{AllGen}}$ ). GSNP_NoDefect: mating scenario where mates were selected based on maximizing an economic score including NTM, sexed semen, semen cost, and a genomic relationship calculated according to VanRaden (2008) ( $\left.\mathrm{g}_{\mathrm{SNP}}\right)$. GSEG1_NoDefect: mating scenario where mates were selected based on maximizing an economic score including NTM, sexed semen, semen cost, and a genomic relationship based on shared genomic segment calculated according to de Cara et al. (2013) with a minimum genomic segment length of 1 cM (g $\mathrm{g}_{\mathrm{SEG} 1}$ ). GSEG4_NoDefect: mating scenario where mates were selected based on maximizing an economic score including NTM, sexed semen, semen cost, and a genomic relationship based on shared genomic segment calculated according to de Cara et al. (2013) with a minimum genomic segment length of 4 cM (g $g_{\mathrm{SEG} 4}$ ).

Table 10. Comparison of outcome of planned matings of 9,841 females for 6 mating scenarios in Nordic Red Dairy Cattle using various comparison criteria ${ }^{1,2}$

\begin{tabular}{|c|c|c|c|c|c|c|}
\hline \multirow[b]{2}{*}{ Comparison criterion } & \multirow[b]{2}{*}{$\begin{array}{l}\text { Max } \\
\text { NTM }\end{array}$} & \multicolumn{5}{|c|}{ Scenarios minimizing relationships } \\
\hline & & $\begin{array}{l}\text { 3Gen } \\
\_ \text {Min }\end{array}$ & $\begin{array}{c}\text { AllGen } \\
\text { _Min }\end{array}$ & $\begin{array}{l}\text { GSNP } \\
\text { _Min }\end{array}$ & $\begin{array}{c}\text { GSEG1 } \\
\text { _Min }\end{array}$ & $\begin{array}{c}\text { GSEG4 } \\
\text { _Min }\end{array}$ \\
\hline Average $a_{3 G e n}$ between parents & 0.033 & 0.004 & 0.007 & 0.013 & 0.013 & 0.013 \\
\hline Average a $a_{A l G}$ between parents & 0.070 & 0.044 & 0.040 & 0.050 & 0.049 & 0.049 \\
\hline Average $g_{S N P}$ between parents & 0.014 & -0.015 & -0.019 & -0.044 & -0.036 & -0.036 \\
\hline Probability of expression of genetic defect (\%) & 0.4 & 0.4 & 0.2 & 0.4 & 0.1 & 0.2 \\
\hline Average cost of semen for a pregnancy $(€)$ & 43.6 & 41.6 & 41.7 & 41.9 & 42.2 & 42.1 \\
\hline Number of bulls used & 39 & 50 & 49 & 50 & 50 & 50 \\
\hline Number of bulls used to a maximum & 20 & 2 & 0 & 0 & 1 & 0 \\
\hline Average $a_{A l l G e n}$ between all planned matings & 0.089 & 0.084 & 0.083 & 0.083 & 0.084 & 0.083 \\
\hline Predicted BTA12 carrier frequency in the next generation $(\%)$ & 12.9 & 12.9 & 10.1 & 13.5 & 10.4 & 11.0 \\
\hline
\end{tabular}

${ }^{1}$ Fifty marketed bulls from VikingGenetics were available for matings (BullVG). Maximum percentage of females per bull and herd set to $5 \%$.

${ }^{2}$ Average NTM level, 5 different genetic relationships, the probability of expression of genetic defect (at BTA12), the average cost of semen for a pregnancy, the number of bulls used, the number of bulls used to a maximum number of doses based on the $5 \%$ of females per bull and herd, average pedigree relationship between all planned matings, and predicted genetic defect at BTA12 carrier frequency in the next generation. MaxNTM: mating scenario where mates were selected based on maximizing an economic score including NTM, sexed semen, and semen cost. 3Gen_Min: mating scenario where mates were selected based on minimizing an economic score including a pedigree relationship including 3 generations of ancestors $\left(\mathrm{a}_{3 \mathrm{Gen}}\right)$. AllGen_Min: mating scenario where mates were selected based on minimizing an economic score including a pedigree relationship including all available ancestors $\left(\mathrm{a}_{\text {AllGen }}\right)$. GSNP_Min: mating scenario where mates were selected based on minimizing an economic score including a genomic relationship calculated according to VanRaden (2008) (gSNP). GSEG1_Min: mating scenario where mates were selected based on minimizing an economic score, including a genomic relationship based on shared genomic segment calculated according to de Cara et al. (2013) with a minimum genomic segment length of 1 cM ( $g_{\text {SEG1 }}$ ). GSEG4_Min: mating scenario where mates were selected based on minimizing an economic score including a genomic relationship based on shared genomic segment calculated according to de Cara et al. (2013) with a minimum genomic segment length of $4 \mathrm{cM}\left(\mathrm{g}_{\mathrm{SEG} 4}\right)$. 
bull and herd resulted in 18 bulls being used to the maximum when using BullVG (Table 7 ), and 8 bulls being used to the maximum when using BullAll (Table 8). Furthermore, changing the maximum number of females per bull and herd from 5\% to $10 \%$ increased the average $\mathrm{a}_{\mathrm{AllGen}}$ among planned matings. The threshold for the maximum number of females per bull and herd thus seems to be most influential for $\mathrm{a}_{\mathrm{AllGen}}$ among planned matings, and we saw only minor differences between scenarios with the same threshold.

The total cost of semen for a pregnancy increased on changing the maximum number of females per bull and herd from $5 \%$ to $10 \%$, because it was more profitable to use bulls from the highest price category more extensively. In general, there were minor differences between scenarios in total cost of semen with the same constraints. Some differences occurred with these constraints if many bulls had NTM close to the price category borders. For example, in BullAll, allowing a maximum of $10 \%$ females per bull and herd meant that many bulls had NTM close to 25, which was the price category border.

\section{Sensitivity Analysis}

Changing the economic consequence of a $1 \%$ increase in inbreeding from $€ 10.0$ to $€ 40.0$ did not change the average $\mathrm{a}_{3 \mathrm{Gen}}(0.07)$ or $\mathrm{a}_{\mathrm{AllGen}}(0.043)$, whereas $\mathrm{g}_{\mathrm{SNP}}$ changed slightly from -0.039 using $€ 40.0$ to -0.036 using $€ 10.0$, average $\mathrm{g}_{\mathrm{SEG} 1}$ changed from 0.141 using $€ 40.0$ to 0.145 using $€ 10.0$, and $\mathrm{g}_{\mathrm{SEG} 4}$ changed from 0.072 using $€ 40.0$ and 0.075 using $€ 10.0$. The average NTM level was kept between 20.6 and 20.8, and no risk of expression of a known genetic defect.

\section{DISCUSSION}

The results we present here show that it is possible to reduce genetic relationships between RDC parents in herds with minimal effect on the genetic level. Including the cost of known recessive genetic defects when optimizing mating strategies eliminated expression of known genetic defects, regardless of the genetic relationship used. There is a long tradition of recording in the Nordic countries, and the strong correlation between pedigree and genomic relationships that we estimated confirms that dairy pedigrees are well documented in the Nordic countries. The results of the sensitivity analysis showed that the mating results are robust in the inbreeding penalty range tested. Furthermore, the genetic relationship was reduced only slightly more when using an economic score designed to only reduce the different genetic relationships than when using an economic score including all available information.

\section{Genetic Relationships}

The correlation between the pedigree relationship and genomic relationship estimates was high, $\geq 0.83$ for $\mathrm{a}_{3 \mathrm{Gen}}$, and $\geq 0.85$ for $\mathrm{a}_{\text {AllGen }}$ (Table 6). Carthy et al. (2019) reported a 0.57 correlation between pedigree relationships and genomic relationship, which is lower than in other studies (0.67-0.88; VanRaden et al., 2011; Pryce et al., 2012). Pryce et al. (2012) concluded that pedigree depth plays a major role for the strength of correlation between pedigree relationships and genomic relationships. They found that when the number of generations of recorded ancestry was $2,4,6$, and 8 , this corresponded to a correlation of $0.67,0.73,0.84$, and 0.87 , respectively. Similarly to our study, they also found that the reduction in genetic relationship was dependent on the way genetic relationships were evaluated. For example, including genomic relationships in an economic score was superior to including pedigree relationships when the goal was to reduce a genomic relationship (Pryce et al., 2012).

Compared with other common dairy cattle breeds, the estimated average genetic relationship between parents was low in the present study. The average pedigree relationship coefficient was approximately half that found by Bérodier et al. (2021) for the Montbéliarde breed, with slightly less pedigree information available (9.7-10.0 equivalent complete generations compared with 12.6 in our study). Carthy et al. (2019) found an average pedigree relationship for Holstein-Friesian in their mating replicates of $6.24 \%$, which is higher than in all our scenarios including genetic relationships (Tables 7-9). However, in Carthy et al. (2019), the only information given was that animals were traced back at least 5 generations, where possible, but with no further information about pedigree completeness and therefore it is hard to compare their values with our study. Our average genomic relationship coefficients were also low compared with those in Makanjuola et al. (2020), who investigated genetic relationships in North American Jersey and Holstein. Using a segment length of 1,000,000 bp, similar to us, their $\mathrm{f}_{\mathrm{SEG}}$ co-ancestry of $15.84 \%$ for Holstein and $23.46 \%$ for Jersey should correspond to half our g $_{\text {SEG1 }}$ value, which for all potential mating with bulls in the set BullVG was 9.44\% ( $\mathrm{g}_{\mathrm{SEG} 1} / 2$ ) (Table 5). The low genetic relationship in RDC can be explained by the different breeds included over time in the RDC breeding program, which has included a mixture of Swedish Red, Danish Red, and Finnish Ayrshire, plus some genes from Norwegian Red, Canadian Ayrshire, American Brown Swiss, and Red Holstein-Friesian (NAV, 2019). We noticed that the mating program favored bulls with a high percentage of breeds other than Swedish Red, Danish Red, and Finnish Ayrshire. All 
bulls we mated qualified for the joint Nordic breeding program (VikingRed), where proportions of up to $25 \%$ of other breeds are allowed (Jakob Lykke Voergaard, product manager, VikingRed, VikingGenetics, personal communication, January 11, 2021). However, some national herdbooks require a lower percentage of other breeds [e.g., the Swedish Red herdbook (Swedish Red Cattle Association, Hörby, Sweden)]. Hence, a higher average relationship coefficient might be obtained with more strict selection of bulls with regard to breed percentages.

\section{Using Genomic or Pedigree Relationships}

An argument for using genomic estimates of inbreeding and relationships is that they do not rely on pedigree data, which can have limited depth or be incorrect (Carthy et al., 2019; Makanjuola et al., 2020; Bérodier et al., 2021). Nordic Cattle Genetic Evaluation had corrected the pedigree in most cases for possible mismatches using genomic information. Hence, we did not fully reveal the benefit that a genomic relationship brings in terms of assigning the right parents to an animal. In Sweden approximately $5 \%$ of genotyped animals have at least one parent incorrectly reported (Lina Baudin, expert in breeding routines, Växa Sverige, personal communication, March 5, 2021). Further, if a population is under selection, the assumption of $50 \%$ chance of each allele being selected is not true. In combination, this leads to pedigree inbreeding often underestimating true inbreeding (as identical by descent from a given base population) compared with $\mathrm{ROH}$-based inbreeding (Forutan et al., 2018). Furthermore, even if pedigree is correct and deep, genomic relationships are more accurate because they consider correctly that genome is transmitted in chromosomes and not as infinite unlinked loci (Hill and Weir, 2011).

Our goal using segment-based relationships was to reduce the number of $\mathrm{ROH}$ in the potential offspring. $\mathrm{ROH}$ are suggested to be a good predictor of inbreeding depression in Finnish Ayrshire (Martikainen et al., 2017, 2020), and also in humans (Szpiech et al., 2013). In theory, $\mathrm{ROH}$ are enriched for deleterious alleles that mainly cause inbreeding depression (Charlesworth and Willis, 2009). In general, long ROH, reflecting new inbreeding, should contain more deleterious alleles than short $\mathrm{ROH}$ due to purging and recombination along with generations (Stoffel et al., 2021). Regions affecting milk and fertility lie between 1 and $14 \mathrm{Mb}$ (Martikainen et al., 2020). In addition, Martikainen et al. (2017) found that pedigree inbreeding did not indicate inbreeding depression for fertility, but inbreeding based on $\mathrm{ROH}$ did. Further, longer regions of $\mathrm{ROH}(>3 \mathrm{Mb}$ ) in Holstein and Jersey have been found to be associated with inbreeding depression in milk (Pryce et al., 2014). However, Zhang et al. (2015) found that enrichment of deleterious variants was significantly higher in short $(<0.1$ to $3 \mathrm{Mb})$ compared with long $(>3 \mathrm{Mb})$ regions in RDC, Holstein, and Jersey. Hence, it is not clear what segment length is optimal for use in segment-based relationships.

The scales of the different genetic relationship coefficients used differed (Table 5). In particular the means were different, but there were also some differences in the standard deviations. Hence, the relationships were difficult to compare directly. However, in general, genomic relationships were better at reducing pedigree relationships than pedigree relationships were at reducing genomic relationships (see e.g., Table 7). For example, the economic score $3 \mathrm{Gen}$ resulted in an average $\mathrm{a}_{3 \mathrm{Gen}}$ of 0.007 and the score GSEG1 resulted in an average $\mathrm{a}_{3 \mathrm{Gen}}$ of 0.014 , compared with $\mathrm{a}_{3 \mathrm{Gen}}$ of 0.028 in Random. Hence, the relative difference in change $[(0.028$ - 0.014)/(0.028 - 0.007)] was 67\%. Furthermore,

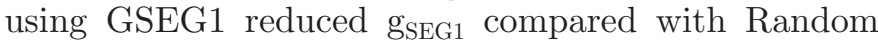
from 0.188 to 0.143 , and 3 Gen reduced $\mathrm{g}_{\mathrm{SEG} 1}$ to 0.167 , that is, the relative difference $[(0.188-0.167) /(0.188$ - 0.143)] was $47 \%$. Furthermore, there were only minor differences for genomic relationships in their ability to reduce pedigree relationships. Hence, using any of the genomic relationships could be an overall better and safer option than using pedigree relationships in keeping all average relationships studied low.

In our study, $\mathrm{a}_{\mathrm{AllG}}$ was better than $\mathrm{a}_{3 \mathrm{Gen}}$ at reducing the average genomic relationships (see e.g., Table 7), suggesting that the Nordic breeding organizations should use more generations when calculating pedigree relationships for nongenotyped animals if they want to control genomic relationships. This finding was expected since the depth of the pedigree plays a major role for the strength of correlation between pedigree relationships and genomic relationships in dairy cattle (Pryce et al., 2012) and similar results have also been reported in chicken (Wang et al., 2014). Furthermore, the use of any genomic relationship worked well to keep other genomic relationships low in this study, which was expected based on the strong correlations between the different genomic relationships (Table 6).

At the population level using OCS, Henryon et al. (2019) suggested that pedigree relationships realize more long-term true genetic gain than genomic relationships. However, Meuwissen et al. (2020) concluded that the choice of relationship matrix depends on which objective it should serve. Genomic relationships based on $\mathrm{ROH}$ resulted in allele frequency changes toward 0.5 , which is clearly unfavorable if the focus is managing genetic defects. Furthermore, using genomic relationships based on VanRaden (2008) resulted in low drift, 
but at the cost of a high rate of increase in homozygosity. A genomic relationship based on linkage analysis, which requires both pedigree and marker information, achieved the highest genetic gain per unit of inbreeding and kept the drift-based inbreeding within the target rate (Meuwissen et al., 2020). A downside with our study is that we only looked one generation ahead, instead of many generations as in OCS studies. Further, farmers are most likely to be mainly interested in their own herd's genetic level and have to rely on breeding organizations to offer bulls with different pedigrees, so that inbreeding depression and mating of carriers of yet unknown defects can be avoided. We were unable to draw any conclusions on which estimate of genetic relationship is best for mating plans with regard to producing offspring with low inbreeding depression and avoiding expression of unknown recessive genetic defects, balanced with high genetic gain. More studies are needed to identify the different types of genetic relationships and their future economic impact for farmers.

\section{Recessive Genetic Defects}

Carrier frequencies of the recessive genetic defects were lower in the mated bulls than in the females (Table 2). The strategy applied in VikingGenetics is to only select a carrier bull if it is genetically superior or has a valuable pedigree for preserving genetic diversity (Jakob Lykke Voergaard, product manager, VikingRed, VikingGenetics, personal communication, January 11, 2021). We observed higher frequencies of genetic defects at BTA12 and BTA23 when we removed the requirement to have marketed semen, and we tried to reflect this with the bull set BullAll (Table 8). An economic score including a penalty for mating 2 carriers effectively eliminated expression of genetic defects. It was more profitable to use the carrier bull on a noncarrier female than on a carrier female. Linear programming can help avoid expression of genetic defects unless the possible matings are restricted (e.g., if only a few noncarrier bulls are available and therefore a carrier bull has to be mated with a carrier female). Bérodier et al. (2021) considered known recessive genetic defects similar to this study and found that linear programming was better than random and sequential mating in reducing the number of genetic defects expressed. However, they could not completely avoid the expression of recessive genetic defects, most likely due to a more restricted bull usage compared with our study. For example, only 8 bulls could be mated to heifers due to restriction of calving ease, and they also included restrictions on availability of semen which we did not consider.

It is worth highlighting that even though the overall frequency (Table 2) was low among all females for all defects except genetic defect at BTA12, the carrier frequencies in some herds were much higher than in other herds (Table 3). The carrier frequency in female candidates could be valuable information for farmers and advisors before deciding on matings in practice, by indicating how different defects should be considered in a specific herd.

We observed higher carrier frequencies in the next generation for the genetic defect at BTA23 using BullAll (Table 8) than in the mated females (Table 2). In general, we saw no clear pattern in the economic score that performed best regarding the carrier frequency in the next generation. Further, we believe that the carrier frequency in the next generation is situation specific for the available bull sets, with regard to the NTM ranking of the carrier bulls, constraints, and genetic relationship. Note that higher carrier frequencies in the next generation could be expected if many bulls carrying defect alleles were represented at the top of the total merit ranking. In reality, this is not expected to occur with the current bull selection strategy at VikingGenetics. However, it could occur if bulls to be used in a herd were selected without consideration of their carrier status.

\section{No Penalty for Genetic Defects}

In scenario GSEG1_NoDefect, the probability of expression of genetic defect at BTA12 was less than in scenarios AllGen_NoDefect, 3Gen_NoDefect, and GSNP_NoDefect (Table 9), and slightly lower than in scenario GSEG4_NoDefect. According to Wu et al. (2020), the genetic defect at BTA12 region is approximately $2.6 \mathrm{Mb}$ and would not be captured in $\mathrm{g}_{\mathrm{SEG} 4}$. This might explain why we saw a slightly higher probability of expression of genetic defect at BTA12 in GSEG4_NoDefect compared with GSEG1_NoDefect. Further, in the scenarios aiming to minimize the different genetic relationships, GSEG1_Min had the lowest probability of expression of genetic defect at BTA12, but AllGen_Min and GSEG4_Min also reduced the probability of expression of genetic defect at BTA12 compared with Random and MaxNTM. Hence, it seems that minimizing some genetic relationships also helped lower, or at least did not increase, the probability of expression of genetic defect at BTA12.

\section{Economic Assumptions}

In the absence of estimates of RDC inbreeding depression, we used the penalty of $€ 24.8$ per $1 \%$ increase in inbreeding, which corresponded to the current version of the Swedish mating program penalty of $1 \mathrm{NTM}$ unit per $1 \%$ increase in inbreeding. This value is in line 
with that estimated for Holstein of US $\$ 25$ (about $€ 20$ ) (Cole, 2015) or US\$24 (Smith et al., 1998). Pryce et al. (2012) used a range up to $\mathrm{AU} \$ 20$ (about $€ 13$ ). When the penalty for $1 \%$ increase in inbreeding was increased to $€ 40$ or decreased to $€ 10$ in our sensitivity analysis, only minor changes in the different average relationships were observed. Furthermore, the average NTM level was kept at the same level, and no expression of known genetic defects was observed. Hence, the mating results seemed not to be sensitive in the inbreeding penalty range tested.

Regarding the economic assumption for the recessive genetic defects, no economic costs have been specifically calculated for the defects considered in our study. Our value of $€ 80$ for an early abortion was in line with Segelke et al. (2016), who estimated a cost of $€ 70$, and Bérodier et al. (2021) who estimated $€ 75$. We assumed the cost of a later abortion or an early calf death to be $€ 160$ (genetic defect SMA, BH2, and at BTA23). Oskarsson and Engelbrekts (2015) estimated the cost to be $€ 100$ to $€ 150$ in Sweden, and NTM calculations estimate the cost to be $€ 200$ to $€ 340$ (Sørensen et al., 2018). Cole (2015) estimated a stillbirth cost of US $\$ 150$.

There are also most likely differences between farms within each country, such as costs associated with genetic defects. The economic score is a relatively simple calculation that demands little computer power, and it could be adjusted to match economic conditions on a specific farm.

\section{Implementation Opportunities}

Many studies have pointed out that linear programming outperforms sequential mating methods because it uses simultaneous rather than sequential solving to find the economically optimal matings for each herd (Sun et al., 2013; Carthy et al., 2019; Bérodier et al., 2021). Therefore, we decided to focus on linear programming and different economic scores and not compare different mating methods. Once the relationships (and NTM and genetic defects) had been calculated, linear programming on a regular laptop maximized the economic score for all herds studied within seconds. This means that the method is suitable for implementing in mating software to be used by advisors and farmers. The most time-consuming calculation of the whole procedure for mating planning was phasing genotypes and extracting the genomic segments, and today this has to be done on a more powerful computer. Genotype phasing and estimating allele frequencies also require information from more than a single farm. This should thus be done at central level and the genetic relationship coefficients should then be made available for downloading to the mating program. Here, $\mathrm{g}_{\mathrm{SNP}}$ used allele frequencies in the current population, which are easy to obtain and often used in genomic evaluation. Further, g gNP was the fastest genomic relationship to calculate and it was powerful at keeping both $\mathrm{g}_{\mathrm{SEG} 1}$ and $\mathrm{g}_{\mathrm{SEG} 4}$ low, making it an efficient implementation option. However, a segment-based relationships should be considered if future studies show they better predict inbreeding depression.

We mated all animals in a herd at a specific time, which would not be the case in a real situation because mating planning is usually performed more than once annually for each herd. For example, in Sweden, mating planning is typically performed 3 to 6 times/yr (Thure Bjerketorp, responsible for breeding advisors, Växa Sverige, personal communication, July 27, 2021). However, we were also only able to study animals born in 2019, because older animals were missing information about genetic defects. Hence, in reality there would be more animals from several birth years to mate, and the number of animals we considered will most likely be in line with a typical mating planning. However, mating planning on a subset of the herd, a third at a time, say, can be expected to be somewhat suboptimal.

The mating scenarios presented here could also be adopted by other breeds or other livestock species. However, we believe the detailed planning at the individual level is quite unique for dairy cattle, at least at the commercial herd level. Further, including genomic relationships and information about genetic defects, similar to this study, requires genotypes of both females and males. An economic score could also be developed for crossbred animals where the focus is to maximize heterosis instead of minimizing parent relationships. In this study, we did not consider ungenotyped animals. Other studies have proposed methods to impute ungenotyped animals [e.g., Carthy et al. (2019) used the method proposed by Gengler et al. (2007)], or one could use the combined genomic and pedigree relationship matrix $\mathbf{H}$ that is used in single-step genomic evaluations, as suggested by Sun et al. (2013).

\section{CONCLUSIONS}

We studied mating allocations in RDC and found that it was possible to reduce genetic relationships between parents with minimal effect on genetic level. Including the cost of known recessive genetic defects entirely eliminated the risk of expression of the 6 known genetic defects. It was possible to reduce genomic relationships between parents with pedigree measures, but it was best done with genomic measures. More studies are needed to identify the different types of genetic relationships and their future economic impact for farmers. Linear programming maximized the economic score for all herds studied within seconds, which means that the 
method is suitable for implementing in mating software to be used by advisors and farmers.

\section{ACKNOWLEDGMENTS}

This study was funded by the Swedish project LivsID, with externally employed doctoral students within food-related research. We offer our special thanks to FABA (Hollola, Finland), Nordic Cattle Genetic Evaluation (Aarhus, Denmark), SEGES (Aarhus, Denmark), and Växa Sverige (Uppsala, Sweden) for providing us with data. We also thank Bérodier et al. (2021) for providing their mating $\mathrm{R}$ script. The authors have not stated any conflicts of interest.

\section{REFERENCES}

Berg, P., J. Nielsen, and M. K. Sørensen. 2006. EVA: Realized and predicted optimal genetic contributions. Book of Abstracts: CD Commun. 27-09. Proc. 8th World Congr. Genet. Appl. Livest. Prod. Belo Horiz., Minas Gerais, Brazil

Berkelaar and Associates. 2020. LpSolve: Interface to "Lp_solve" v. 5.5 to solve linear/integer programs. Accessed January 26, 2021. https://rdrr.io/cran/lpSolve/.

Bérodier, M., P. Berg, T. Meuwissen, D. Boichard, M. Brochard, and V. Ducrocq. 2021. Improved dairy cattle mating plans at herd level using genomic information. Animal 15:100016. https://doi.org/10 $.1016 /$ j.animal.2020.100016.

Borchersen, S. 2019. Launch of improved EuroGenomics genotyping beadchip: EuroG MD. Accessed April 27, 2021. https:// www.eurogenomics.com/actualites/eurogenomics-new-eurog-md -beadchip.html.

Browning, B. L., and S. R. Browning. 2013. Improving the accuracy and efficiency of identity-by-descent detection in population data. Genetics 194:459-471. https://doi.org/10.1534/genetics.113 .150029 .

Browning, S. R., and B. L. Browning. 2007. Rapid and accurate haplotype phasing and missing-data inference for whole-genome association studies by use of localized haplotype clustering. Am. J. Hum. Genet. 81:1084-1097. https://doi.org/10.1086/521987.

Burnell, M. 2019. The use of sexed semen in dairy herds. Livestock (Lond) 24:282-286. https://doi.org/10.12968/live.2019.24.6.282.

Carthy, T. R., J. McCarthy, and D. P. Berry. 2019. A mating advice system in dairy cattle incorporating genomic information. J. Dairy Sci. 102:8210-8220. https://doi.org/10.3168/jds.2019-16283.

Charlesworth, D., and J. H. Willis. 2009. The genetics of inbreeding depression. Nat. Rev. Genet. 10:783-796. https://doi.org/10.1038/ nrg2664.

Cole, J. B. 2015. A simple strategy for managing many recessive disorders in a dairy cattle breeding program. Genet. Sel. Evol. 47:94. https://doi.org/10.1186/s12711-015-0174-9.

de Cara, M. Á. R., B. Villanueva, M. Á. Toro, and J. Fernández. 2013. Using genomic tools to maintain diversity and fitness in conservation programmes. Mol. Ecol. 22:6091-6099. https://doi.org/10 $.1111 / \mathrm{mec} .12560$.

EFFAB. 2020. Code of good practice. Accessed February 2, 2021. https://www.responsiblebreeding.eu/uploads/2/3/1/3/23133976/ animal_breeding___brochure_code-efabar.pdf.

Fikse, F., and M. Kargo. 2020. The economic value of NTM. Accessed February 2, 2021. https://www.nordicebv.info/wp-content/ uploads/2020/11/The-economic-value-of-NTM_final.pdf.

Forutan, M., S. Ansari Mahyari, C. Baes, N. Melzer, F. S. Schenkel, and M. Sargolzaei. 2018. Inbreeding and runs of homozygosity before and after genomic selection in North American Holstein cattle. BMC Genomics 19:98. https://doi.org/10.1186/s12864-018 $-4453-\mathrm{z}$.
Gautier, M., T. Faraut, K. Moazami-Goudarzi, V. Navratil, M. Foglio, C. Grohs, A. Boland, J.-G. Garnier, D. Boichard, G. M. Lathrop, I. G. Gut, and A. Eggen. 2007. Genetic and haplotypic structure in 14 european and african cattle breeds. Genetics 177:1059-1070. https://doi.org/10.1534/genetics.107.075804.

Gengler, N., P. Mayeres, and M. Szydlowski. 2007. A simple method to approximate gene content in large pedigree populations: Application to the myostatin gene in dual-purpose Belgian Blue cattle. Animal 1:21-28. https://doi.org/10.1017/S1751731107392628.

Guarini, A. R., M. Sargolzaei, L. F. Brito, V. Kroezen, D. A. L. Lourenco, C. F. Baes, F. Miglior, J. B. Cole, and F. S. Schenkel. 2019 Estimating the effect of the deleterious recessive haplotypes AH1 and AH2 on reproduction performance of Ayrshire cattle. J. Dairy Sci. 102:5315-5322. https://doi.org/10.3168/jds.2018-15366.

Henryon, M., H. Liu, P. Berg, G. Su, H. M. Nielsen, G. T. Gebregiwergis, and A. C. Sørensen. 2019. Pedigree relationships to control inbreeding in optimum-contribution selection realise more genetic gain than genomic relationships. Genet. Sel. Evol. 51:39. https:// doi.org/10.1186/s12711-019-0475-5.

Hill, W. G., and B. S. Weir. 2011. Variation in actual relationship as a consequence of Mendelian sampling and linkage. Genet. Res. (Camb.) 93:47-64. https://doi.org/10.1017/S0016672310000480.

Kadri, N. K., G. Sahana, C. Charlier, T. Iso-Touru, B. Guldbrandtsen, L. Karim, U. S. Nielsen, F. Panitz, G. P. Aamand, N. Schulman, M. Georges, J. Vilkki, M. S. Lund, and T. Druet. 2014. A 660-Kb deletion with antagonistic effects on fertility and milk production segregates at high frequency in Nordic Red Cattle: Additional evidence for the common occurrence of balancing selection in livestock. PLoS Genet. 10:e1004049. https://doi.org/10.1371/journal .pgen.1004049.

Krebs, S., I. Medugorac, S. Rother, K. Strasser, and M. Forster. 2007. A missense mutation in the 3-ketodihydrosphingosine reductase FVT1 as candidate causal mutation for bovine spinal muscular atrophy. Proc. Natl. Acad. Sci. USA 104:6746-6751. https://doi .org/10.1073/pnas.0607721104.

Maignel, L., D. Boichard, and E. Verrier. 1996. Genetic variability of French dairy breeds estimated from pedigree information. No 14 1996 Proc. Open Sess. Interbull Annu. Meet. 7.

Makanjuola, B. O., F. Miglior, E. A. Abdalla, C. Maltecca, F. S. Schenkel, and C. F. Baes. 2020. Effect of genomic selection on rate of inbreeding and coancestry and effective population size of Holstein and Jersey cattle populations. J. Dairy Sci. 103:5183-5199. https://doi.org/10.3168/jds.2019-18013.

Martikainen, K., M. Koivula, and P. Uimari. 2020. Identification of runs of homozygosity affecting female fertility and milk production traits in Finnish Ayrshire cattle. Scientific Rep. 10:3804. https:// doi.org/10.1038/s41598-020-60830-9.

Martikainen, K., A. M. Tyrisevä, K. Matilainen, J. Pösö, and P. Uimari. 2017. Estimation of inbreeding depression on female fertility in the Finnish Ayrshire population. J. Anim. Breed. Genet. 134:383-392. https://doi.org/10.1111/jbg.12285.

Meuwissen, T., and Z. Luo. 1992. Computing inbreeding coefficients in large populations. Genet. Sel. Evol. 24:305-313. https://doi.org/10 .1186/1297-9686-24-4-305.

Meuwissen, T. H. E., A. K. Sonesson, G. Gebregiwergis, and J. A. Woolliams. 2020. Management of genetic diversity in the era of genomics. Front. Genet. 11:880. https://doi.org/10.3389/fgene.2020 .00880 .

NAV. 2019. NAV routine genetic evaluation of dairy cattle - Data and genetic models. Accessed Aug. 22, 2019. https://www.nordicebv .info/wp-content/uploads/2019/06/NAV-routine-genetic -evaluation-04062019.pdf.

Olsen, H. F., S. Tenhunen, N. I. Dolvik, D. I. Våge, and G. Klemetsdal. 2020. Segment-based coancestry, additive relationship and genetic variance within and between the Norwegian and the Swedish Fjord horse populations. Acta Agric. Scand. Anim. Sci. 69:118-126. https://doi.org/10.1080/09064702.2019.1711155.

Oskarsson, M., and E. Engelbrekts. 2015. Kostnader för hälsostörningar hos mjölkkor. February 2, 2021. https://docplayer.se/28330924 -Kostnader-for-halsostorningar-hos-mjolkkor.html. 
Pryce, J. E., M. Haile-Mariam, M. E. Goddard, and B. J. Hayes. 2014. Identification of genomic regions associated with inbreeding depression in Holstein and Jersey dairy cattle. Genet. Sel. Evol. 46:71. https://doi.org/10.1186/s12711-014-0071-7.

Pryce, J. E., B. J. Hayes, and M. E. Goddard. 2012. Novel strategies to minimize progeny inbreeding while maximizing genetic gain using genomic information. J. Dairy Sci. 95:377-388. https://doi.org/10 $.3168 /$ jds.2011-4254.

R Core Team. 2020. A language and environment for statistical computing. R Foundation for Statistical Computing.

Sahana, G., T. Iso-Touru, X. Wu, U. S. Nielsen, D.-J. de Koning, M. S. Lund, J. Vilkki, and B. Guldbrandtsen. 2016. A 0.5-Mbp deletion on bovine chromosome 23 is a strong candidate for stillbirth in Nordic Red cattle. Genet. Sel. Evol. 48:35. https://doi.org/10 $.1186 / \mathrm{s} 12711-016-0215-\mathrm{z}$.

Sargolzaei, M. 2014. SNP1101 User's Guide. Version 1.0.

Sargolzaei, M., J. P. Chesnais, and F. S. Schenkel. 2014. A new approach for efficient genotype imputation using information from relatives. BMC Genomics 15:478. https://doi.org/10.1186/1471 $-2164-15-478$.

Schwarzenbacher, H., J. Burgstaller, F. R. Seefried, C. Wurmser, M. Hilbe, S. Jung, C. Fuerst, N. Dinhopl, H. Weissenböck, B. FuerstWaltl, M. Dolezal, R. Winkler, O. Grueter, U. Bleul, T. Wittek, R. Fries, and H. Pausch. 2016. A missense mutation in TUBD1 is associated with high juvenile mortality in Braunvieh and Fleckvieh cattle. BMC Genomics 17:400. https://doi.org/10.1186/s12864 $-016-2742-y$.

Segelke, D., H. Täubert, F. Reinhardt, and G. Thaller. 2016. Considering genetic characteristics in German Holstein breeding programs. J. Dairy Sci. 99:458-467. https://doi.org/10.3168/jds.2015-9764.

Smith, L. A., B. G. Cassell, and R. E. Pearson. 1998. The effects of inbreeding on the lifetime performance of dairy cattle. J. Dairy Sci. 81:2729-2737. https://doi.org/10.3168/jds.S0022-0302(98)75830 $-8$.

Sonesson, A. K., J. A. Woolliams, and T. H. Meuwissen. 2012. Genomic selection requires genomic control of inbreeding. Genet. Sel. Evol. 44:27. https://doi.org/10.1186/1297-9686-44-27.

Sørensen, L. P.. J. Pedersen, M. Kargo, U. S. Nielsen, F. Fikse, J.-A. Eriksson, J. Pösö, R. S. Stephansen, and P. Aamand. 2018. Review of Nordic total merit index full report November 2018. https: //www.nordicebv.info/wp-content/uploads/2018/11/2018.11.06 -NTM-2018-report-Full.pdf.

Stoffel, M. A., S. E. Johnston, J. G. Pilkington, and J. M. Pemberton. 2021. Genetic architecture and lifetime dynamics of inbreeding depression in a wild mammal. Nat. Commun. 12:2972. https://doi .org/10.1038/s41467-021-23222-9.
Strandén, I., and K. Vuori. 2006. RelaX2 program for pedigree analysis, user's guide for version 1.65. Pages 27-30 in Proceedings of the 8th World Congress on Genetics Applied to Livestock Production. Instituto Prociência.

Sun, C., P. M. VanRaden, J. R. O'Connell, K. A. Weigel, and D. Gianola. 2013. Mating programs including genomic relationships and dominance effects. J. Dairy Sci. 96:8014-8023. https://doi .org/10.3168/jds.2013-6969.

Szpiech, Z. A., J. Xu, T. J. Pemberton, W. Peng, S. Zöllner, N. A. Rosenberg, and J. Z. Li. 2013. Long runs of homozygosity are enriched for deleterious variation. Am. J. Hum. Genet. 93:90-102. https://doi.org/10.1016/j.ajhg.2013.05.003.

VanRaden, P. M. 2008. Efficient methods to compute genomic predictions. J. Dairy Sci. 91:4414-4423. https://doi.org/10.3168/jds .2007-0980.

VanRaden, P. M., K. M. Olson, D. J. Null, and J. L. Hutchison. 2011. Harmful recessive effects on fertility detected by absence of homozygous haplotypes. J. Dairy Sci. 94:6153-6161. https://doi.org/10 $.3168 /$ jds.2011-4624.

Wang, H., I. Misztal, and A. Legarra. 2014. Differences between genomic-based and pedigree-based relationships in a chicken population, as a function of quality control and pedigree links among individuals. J. Anim. Breed. Genet. 131:445-451. https://doi.org/ 10.1111/jbg. 12109 .

Woolliams, J. A., and E. A. Mäntysaari. 1995. Genetic contributions of Finnish Ayrshire bulls over four generations. Anim. Sci. 61:177187. https://doi.org/10.1017/S1357729800013709.

Wu, X., M. Mesbah-Uddin, B. Guldbrandtsen, M. S. Lund, and G. Sahana. 2020. Novel haplotypes responsible for prenatal death in Nordic Red and Danish Jersey cattle. J. Dairy Sci. 103:4570-4578. https://doi.org/10.3168/jds.2019-17831.

Zhang, Q., B. Guldbrandtsen, M. Bosse, M. S. Lund, and G. Sahana. 2015. Runs of homozygosity and distribution of functional variants in the cattle genome. BMC Genomics 16:542. https://doi.org/10 $.1186 / \mathrm{s} 12864-015-1715-\mathrm{x}$.

\section{ORCIDS}

C. Bengtsson @ \ttps://orcid.org/0000-0001-5784-2557

H. Stålhammar @ https://orcid.org/0000-0002-7354-651X

J. R. Thomasen (자 https://orcid.org/0000-0001-7068-0572

S. Eriksson ๑ https://orcid.org/0000-0003-3357-5065

W. F. Fikse @ https://orcid.org/0000-0003-0578-0184

E. Strandberg @ https://orcid.org/0000-0001-5154-8146 